\title{
Modeling relation between hospital efficiency and customer satisfaction of tertiary hospitals: A case of data envelopment analysis
}

\author{
Suresh Chandra Akula*, Pritpal Singh
}

Suresh Chandra Akula*, Pritpal

Singh

'Mittal school of business, Lovely Professional University, G.T. Road, Phagwara,

Punjab 144411, INDIA.

\section{Correspondence}

\section{Suresh Chandra Akula}

Mittal school of business, Lovely

Professional University, G.T. Road

Phagwara, Punjab144411, INDIA

E-mail: akulasureshchandra@gmail.com

History

- Submission Date: 02-09-2021:

- Review completed: 11-10-2021:

- Accepted Date: 18-10-2021.

DOI : 10.5530/pj.2021.13.194

Article Available online

http://www.phcogj.com/v13/i6

\section{Copyright}

(C) 2021 Phcogj.Com. This is an openaccess article distributed under the terms of the Creative Commons Attribution 4.0 International license.

\begin{abstract}
In the present circumstance, it has turned out to be difficult for hospitals to guarantee increasingly productive methods for administrations. Under the current conditions, it is fundamental to discover the fitting asset blend and its use. So also, it is important to distinguish the sources of relative cost wastefulness - specialized and allocated both. The center point of this study is on surveying the hospitals in efficiency terms, for example, the perfect measure of inputs to deliver a given degree of output. The other inspiration driving this investigation has been to see how to address an issue of benchmarking in hospitals. Data envelopment analysis utilizes an amazing procedure of linear programming to help in doing this. The research of the study incorporates two different aspects one is to evaluate efficiency of hospitals considered for study and another is find satisfaction level of patients from these hospitals to find association among both these dimensions, Moreover, this study gives the proof that medical hospital size has a critical negative impact on efficiency of hospital i.e. Present research indicates that smaller hospitals have a higher level of efficiency than larger and medium-size hospitals, smaller size hospitals average efficiency is .80. The average efficiency of medium size hospitals is .75 and the large hospital is .71. Results of research also explains that efficiency is considered to be negative moderator between relation of number of specialized doctors and patient satisfaction. Results of study suggested that higher level of efficiency level of hospitals lessen the positive effect of specialized doctors on patient satisfaction. Key words: Hospital efficiency, Customer satisfaction, Negative moderator, Association.
\end{abstract}

\section{INTRODUCTION}

Data envelopment analysis utilizes an amazing procedure of linear programming to help in doing this. The research of the study incorporates two different aspects one is to evaluate efficiency of hospitals considered for study and another is find satisfaction level of patients from these hospitals to find association among both these dimensions, For evaluating efficiency of hospitals data envelopment analysis technique is used which consist of linear mathematical programs to evaluate efficiency and for satisfaction level the specialists working in Government and Private hospitals of Punjab considered for study. To validate content of instrument and the inpatients getting treatment in either Private or Government medical hospital in Punjab considered as tertiary hospitals. The area of the research is Punjab which has been positioned among the most elevated per capita salary states for most recent years. Additionally, the Punjab hospital area has encountered real changes in the hospital division with the formation of Punjab Health System Corporation. Further, the patients who had been admitted to the medical hospitals for over at least one day and one-night corporate into the study, which is minimum criteria to be considered a patient as inpatient.

The analysis initiated with the calculation of efficiency of hospitals decided for study. Hospitals for the study had been selected from three different areas of Punjab i.e. Malwa, Majha and Doaba. Hospitals from each area were selected including hospitals from Chandigarh. Hospitals are selected based on quota sampling. Hospitals of different sizes are selected and size is dependent upon bed strength of hospitals. Result explains that efficiency is considered to be negative moderator between relation of number of specialized doctors and patient satisfaction, Results in table suggested that higher level of efficiency level of hospitals lessen the positive effect of specialized doctors on patient satisfaction. In this way, medical hospital productivity variable applies a negative control between accessibility of specialists and patient satisfaction, as we theorized. Moreover, discoveries give the proof that medical hospital size has a critical negative impact on patient satisfaction. To further prove this research analysis is done to support hypothesis which also proves that high level of hospital efficiency lessen the positive effect of specialist doctors on patient satisfaction.

\section{Need for study}

In the present hospital and healthcare circumstances it has turned out to be difficult for hospital in Punjab to guarantee increasingly productive methods for their administrations. Data envelopment analysis if used properly can empower authorities over best utilization of inputs and outputs and to decide proper mix of inputs required to produce output. In that case, it will become very important for hospitals whether private or government to optimally utilize their existing resources, Data envelopment analysis is technique is formulated to find operational efficiency in form of logical and scale efficiency of organization to decide their benchmark and

Cite this article: Akula SC, Singh P. Modeling relation between hospital efficiency and customer satisfaction of tertiary hospitals: A case of data envelopment analysis. Pharmacogn J. $2021 ; 13(6): 1527-1532$. 
operate according to benchmark or if there is no benchmark then set benchmark. In the present situation, this most important to contain costs and guarantee efficiency of healthcare services and DEA can provide proper insights to working of organization. Under the current conditions, it is fundamental to discover the fitting asset blend and its use. So likewise, it is important imperative to recognize the sources of relative cost inefficiency - concentrated core and assign both. The center purpose of this assessment is on studying the medical hospital facilities in specific terms, for instance, the ideal proportion of inputs for a given level of output. The other motivation driving this study is how to address process of benchmarking under changing circumstance in the medical hospitals. Golany (1988) clarifies that opening of private medical inclusion part in the post-1991 period; capability with which the benefits are provided would acknowledge progressively centrality in the healthcare industry. The requirement for creating productivity parameters and standard, which aides in the positioning of hospitals, is prone to accept basic significance.

This procedure gives a target rule to break down and assess the efficiency of hospitals in a relative setting. Golany \& Tamir (1995) proposes that the DEA approach does not force rule from outside yet attempts to develop it from inside the framework. The rising patterns of healthcare expenses and quickly expanding requests have constrained medicinal services suppliers to concentrate more on efficiency and quality Golan (1988) explains the compelling usage of constrained assets has turned into a basic issue for medical hospital the executives. In this way, hospital establishments are typically compelled to build up their tasks both as far as assets they use and as far as amount and nature of their outcomes the shortage of healthcare part resources is particularly risky.

In developing nations where unforeseen shortcoming condition is one of the most enormous impediments for fiscal improvement and welfare. Goldar (1986) proposes crisis facility focuses of developing nations should concentrate on the productive utilization of points of interest and broadening quality in their operational undertakings.

According to The Hindu business line ,2018 In India, the construction of cost per bed can be as low as about $\$ 43,000$. In this new trend, specialists are holding hands with investors, Drug supply firms and clinical hardware sellers to set up specialist hospitals at low costs. While the expense of setting up a quality hospital is as high as about Rs. 95 lakh (about $\$ 152,000$ ) per bed and one needs to sit for around five years to get a return on investment, the speculation required in this model is about Rs. 20 -25 lakh (about $\$ 43,000$ to $\$ 54,000$ ) per bed and the return on investment in under three years. This model has pulled in light of a legitimate concern for the Businessmen particularly investors. "This will be the pattern in future, as of now most business people are not inspired by ventures which require Rs. 100 crore speculation for 100-bedded hospitals and wait for five years to get returns," said Muralidharan Nair, Partner-Business Advisory Services, Ernst and Young. The Bangalorebased Narayana Hrudayalaya Hospitals (NH), which as of now has 14 clinics with 6,000 beds in seven States, is wanting to contribute almost Rs.5,000 crore to add 30,000 beds in five years by opening hospitals. The organization will contribute Rs 25-30 crore on every one of these hospitals by, utilizing pre-assembled development materials and one is already under construction and being worked by L\&T in Mysore to construct 300-bed multi-specialty hospital with $\$ 6$ million to $\$ 7$ million (Rs 35 crore) as against evaluations of $\$ 25$ million.it is also mention that to increase efficiency and effectiveness of treatment various facilities will be there in hospitals like video monitoring of patients, electronic data records, day care facilities at affordable charges .

\section{MATERIALS AND METHODS}

\section{Research Gap}

As the demand for healthcare services in India is increasing because of many reasons which include awareness for a preventive health checkup,
Increasing population, Complexity of disease and availability are major contributors to this. Demand of health services are increasing but availability of health services are still big issue. Among health service providers in specialized care, Private sector in Punjab is at forefront and covering most of area and population for providing health services. But still according to world health statistics report India is performing below average with 9 beds for 1000 patients which is very below global average. In the present circumstance, it has turned out to be difficult for hospitals in Punjab to guarantee increasingly productive methods for administrations. Under the current conditions, it is fundamental to discover the fitting asset blend and its use to provide quality services to patients. So also, it is important to distinguish the sources of relative cost wastefulness - specialized and allocate both. The center point of this study is on surveying the hospitals in efficiency terms, for example, the perfect measure of inputs to deliver a given degree of output and relate it with patient satisfaction. The other inspiration driving this investigation has been to see how to address an issue of benchmarking in hospitals. In that case, it will become very important for hospitals whether private or government to optimally utilize their existing resources, Data envelopment analysis is technique which is formulated to find operational efficiency in form of logical and scale efficiency of organization and to decide their benchmark and operate according to benchmark or if there is no benchmark then set benchmark. ${ }^{1}$ Data envelopment analysis utilizes an amazing procedure of linear programming to help in doing this. The research of the study incorporates two different aspects one is to evaluate efficiency of hospitals considered for study and another is find satisfaction level of patients from these hospitals to find association among both these dimensions, For evaluating efficiency of hospitals data envelopment analysis technique is used which consist of linear mathematical programs to evaluate efficiency and for satisfaction level the specialists working in Government and Private hospitals of Punjab considered for study to validate content of instrument and the inpatients getting treatment in either Private or Government medical hospital in Punjab considered as tertiary hospitals according to services provided considered for study.

\section{Target Population}

This research incorporates two different aspects one is to evaluate efficiency of hospitals considered for study and another is finding satisfaction level of patients from these hospitals and to find association among both these dimensions, For calculating efficiency super specialty hospitals are considered from all three areas of Punjab Majha, Malwa and Doaba according to three different sizes of i.e. small Size hospitals is between more than 40 and 70, medium size between 70 to 100 and big size more than 100 based on number of beds. Inpatients getting treatment from these hospitals are considered for finding patient satisfaction level among patients for these hospitals. The selection of hospitals was made from the list of the hospitals being run by doctors registered with the Indian Medical Association. Government and the private tertiary level hospitals with bed strength more than 40 were chosen for study from each of the area selected for the study

\section{Sample size}

For validating contents of questionnaire 30 specialists working in Government and Private hospitals of Punjab are considered to and find patient satisfaction the 960 inpatients getting treatment in either Private or Government medical hospital in Punjab considered as tertiary hospitals according to services provided considered for study. The area of the research is Punjab which has been positioned among the one of the most elevated per capital salary states for many years. The feedback of the specialists for content validity and many in-patients has been taken for accomplishing the objectives of the study. Further, the patients who had been admitted to the medical hospitals for over at 
least one day and one-night corporate into the study, which is minimum criteria to be considered a patient as inpatient. In this study has the data had been collected from 48 tertiary hospitals from cities of all the areas of Punjab, in particular, Majha, Malwa and Doaba and these are those hospitals which are considered as referral for those adjoin areas. Patients admitted to the chosen medical hospitals made the structure of the study. Patients in multispecialty medical hospitals, especially experiencing tertiary-level healthcare illnesses, include the population for the investigation. Patients experiencing explicitly eight kinds of tertiary-level healthcare ailments have been considered as respondents

\section{Sample selection of hospitals}

The selection of hospitals was made from the list of the hospitals being run by doctors registered with the Indian Medical Association. Government and the private tertiary level hospitals with bed strength more than 40 were chosen for study from each of the districts selected for the study. Out of the all list, 48 tertiary hospitals were selected. Hospitals are selected based on quota sampling. Quota sampling is done on basis of size of hospital, according to objective of this research different sized hospitals are required and three different sizes of tertiary hospitals are considered i.e small size is between more than 40 and 70 , medium size between 70 to 100 and big size more than 100 based on number of beds. Kamakura (2018) explains quota sampling is best to give point by point data about the challenges in acquiring the differentiation in sampling data. Quota sampling is used in this research as it is considered as most basic and usual way to do research and sub point of distinction added are number of beds, data was collected from hospitals according to size of hospitals either large size, small size and medium size hospitals and about the research outcomes achievement.

\section{Sample selection of inpatients}

Patient satisfaction is is significant to all including health service providers, administrations providers, the patients (clients) themselves and other outsider accomplices in the medicinal services industry giving healthcare administrations (Figure 1). For healthcare providers ensuring that patients are satisfied requires consistent effort. It is too fundamental to them that the certifiable state of client satisfaction must be maintained. To achieve this, healthcare providers set out various researches to find the satisfaction level of the patients and discover strategies for serving them better. Be that, choosing the correct instrument and procedure to involve satisfaction level of customers is a significant test for healthcare suppliers/specialists. This chapter endeavors to clarify what establishes satisfaction in the point of view of the customers (patient attendants) and the method(s) that can be embraced by healthcare suppliers/analysts to use already revealed factors from literature that are answerable for customer satisfaction or patient satisfaction

The survey was created to study satisfaction among patients of 48 hospitals; the survey was created in two configurations Punjabi language and English language. As target population were from

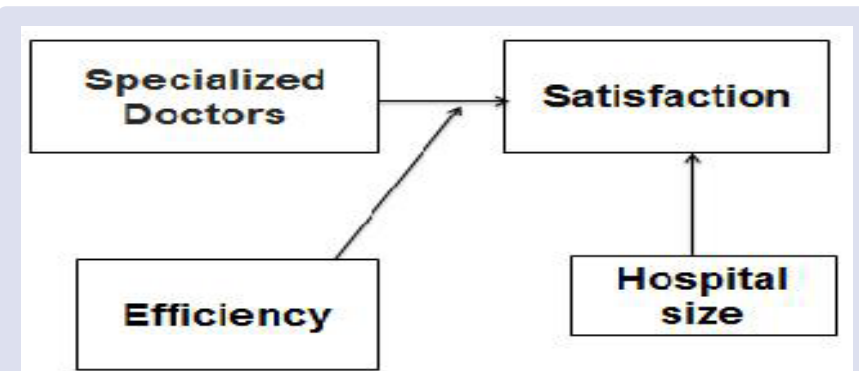

Figure 1: Model to find the association of patient satisfaction and efficiency.
Punjab that is the reason Punjabi language survey was created in this study, Likert scale has been used to evaluate respondents' frames of mind towards healthcare administrations. It must consist of an identical number of good clarifications concerning the outlook of the respondents. ${ }^{2-6}$ Considering the care level of the respondents, a great deal of 42 questions, considering this scale, has been distributed to the respondents. Distinctive measurement dimensions have in like manner been considered to understand the different behaviors of respondents. Patients in multi quality 48 tertiary emergency hospitals of Punjab, particularly encountering tertiary-level diseases, arranged in urban regions incorporate into study. Patients encountering expressly eight sorts of tertiary-level prosperity ailments have been considered as respondents in survey addresses comprise of eight unique measurements which are discussed about in chapter 4 of information investigation of this study. ${ }^{7-11}$

\section{Inputs and outputs from the hospital for data envelopment analysis}

Inputs include beds, number of doctors, Nurses specialized equipment's, and Outpatient department hours per week of working, laboratory hours per week and paramedical staff supporting staff doctors and operating equipment's. and administrative staff. ${ }^{12}$ This data was collected from hospitals to calculate efficiency. Output for calculating efficiency are outpatient visits, Inpatients and laboratory cases, Maternal and child healthcare all these are types of cases treated and number of cases.

\section{RESULTS AND DISCUSSION}

In this part of the research, the emphasis is on analyzing data in three different orientation first of all data was analyzed to calculate the efficiency of hospitals decided for study. Secondly, satisfaction level of patients had been analyzed, To find satisfaction level of patient's questionnaire was framed and thirdly interpretation had been done to analyze relation and association between operational efficiency of hospitals and customer satisfaction.

\section{Efficiency calculation and assessing customer satisfaction}

DEA Frontier coded by Professor Joe Zhu (Professor of Operational Research Foise Business College) for Data Envelopment Analysis (DEA) models. This computer programs is made subject to Professor Zhu's significant DEA teaching experience. The software is made by Professor Zhu with a ultimate objective to restrict the credibility of the presentation of DEA models during coding.

In 'first stage efficiency of hospitals were analyzed, data envelopment analysis was utilize here to analyze and evaluate the efficiency of the hospital. Present research indicates that smaller hospitals have a efficiency more than larger size and mid-size medical hospitals as demonstrated in above table smaller size hospitals average efficiency is .80 . The mean efficiency of medium size hospitals is .75 and large hospital is .71. As per outcomes, small size medical hospitals are generally more efficient and have higher patient satisfaction compared with different kinds of hospitals. To find satisfaction level among patients two questionnaires separate for inpatients and outpatients are developed in English and Punjabi language. Target is to get questionnaire filled from 25 inpatients each hospital to make total to 1200 responses..$^{13}$ But almost 30 responses are collected from each hospital to compensate the loss of incorrect and inappropriate filled questionnaire and 20 responses conceded for study collectively count up to 960 responses. Then patient satisfaction level of tertiary hospitals of small size (0.92) is more than other two types of hospitals $(0.88,0.85$, separately) This study shows surveying satisfaction of patients is basic, simple and financially savvy route for assessment of hospital benefits and has helped finding that indoor patients conceded in tertiary Hospitals of Punjab were progressively happy with Conduct of specialists yet issue lies with the accessibility of essential areas and 
disappointment was seen as additional as to in the toilets and the wards. Bed sheets, drinking water, fans accessibility ought to be a few earnest issues requiring concern. Time to arrive at labs is likewise an issue is to be concerned by management for better understand patient needs.

The results show that efficiency of hospitals is having positive relation with patient satisfaction. It means in efficient hospitals patients are more satisfied as compared to inefficient hospitals .As in results of this study small scale hospitals are more efficient as compared to large scale hospitals so the patient of small scale hospitals are also more satisfied as compared to patients of large scale hospitals .Overall efficiency is positively effecting satisfaction but as discussed earlier efficiency cannot be increased to some specific limit which will effect quality now very important another question is how hospital efficiency changes the relationship between patient satisfaction out the and specialist doctor's. To find answer to this question following model is used:

$\mathrm{Y}=\mathrm{B}_{0}+\mathrm{B}_{1} \mathrm{X}_{1}+\mathrm{B}_{2} \mathrm{X}_{2}+\mathrm{B}_{3} \mathrm{X}_{3}$ Model 1

In this model 1 patient satisfaction is represented by $\mathrm{Y}, \mathrm{X} 1$ is represented by several specialized doctors, $\mathrm{X} 2$ is represented by hospital efficiency and $\mathrm{X} 3$ is represented by hospital size

\section{$\mathrm{Y}=\mathrm{B}_{0}+\mathrm{B}_{1} \mathrm{X}_{1}+\mathrm{B}_{2} \mathrm{X}_{2}+\mathrm{B}_{3} \mathrm{X}_{3}+\mathrm{B}_{4} \mathrm{X} 1 \mathrm{X} 2$ Model 2}

Model 2 B4X1X2 represent the moderator effect of hospital efficiency on the relationship between patient satisfaction and the availability of specialized doctors

When regression is applied on first model following results are following results are obtained.

This model is significant at $\mathrm{p}<.05$ level here the number of specialized doctors increases patient satisfaction providing support to hypothesis $\mathrm{H} 1 \mathrm{~b} 2=.186$. However, hospital size is harming patient satisfaction b3 $=--.033$. But efficiency is not having a significant effect on patient satisfaction there might be the case indirect relation between hospital efficiency and patient satisfaction .one of our major research question is how efficiency the form of relationship between no of specialized doctors and patient satisfaction to evaluate this second-stage regression analysis is done with moderator effect. For that second model is tested for regression to find relationship.

When regression is applied for second model following results are obtained.

Thus, hospital efficiency variable exerts a negative moderation between doctors and patient satisfaction. The second model is also significant and regression analysis result explains that efficiency is considered to be negative moderator between relation of number of specialized doctors and patient satisfaction, Results in tables 1-3 suggested that higher level of efficiency level of hospitals lessen the positive effect of specialized doctors on patient satisfaction In this way, medical hospital productivity variable applies a negative control between accessibility of specialists and patient satisfaction, as we theorized.

To further prove this that medical hospital size has a critical negative impact on patient satisfaction research analysis is which also proves that high level of hospital efficiency lessen the positive effect of specialist doctors on patient satisfaction. For conducting this research hospitals are divided on basis of size into different parts high efficient and low efficient hospitals. ${ }^{5}$

Results of tables 4-6 shows that more efficient hospitals decrease the positive effect of specialized doctors on patient satisfaction. In highly efficient hospitals result of specialized doctors on satisfaction is less and non-significant. While on less efficient hospitals comparatively there is stronger effect of specialized doctors on patient satisfaction.
Table 1: Construction of cost per bed.

\begin{tabular}{|c|c|c|}
\hline & $\begin{array}{l}\text { Indian } \\
\text { Rupee }\end{array}$ & Beds \\
\hline $\begin{array}{l}\text { Speculation in market for Building Good quality bed of } \\
100 \text { bedded hospital }\end{array}$ & 95 lakhs & 1 \\
\hline Speculation cost in new model per bed & 27-34 lakhs & 1 \\
\hline $\begin{array}{l}\text { Narayana Hrudayalaya Hospitals (NH) built Speculations } \\
\text { for } 100 \text { beds }\end{array}$ & 25-35crore & 100 \\
\hline $\begin{array}{l}\text { NH has provided } 300 \text { beds at a cost of Rs. } 110 \text { crore. } \\
\text { "Economy of scale, sharing infrastructure and expertise } \\
\text { reduces cost of operation and to achieve efficiency }\end{array}$ & 110 crore & 300 \\
\hline $\begin{array}{l}\text { Company's second super-specialty Health City complex, } \\
\text { offering all healthcare facilities at one place, is coming up } \\
\text { on a } 37 \text {-acre plot in Ahmedabad. With a total investment } \\
\text { of Rs } 600 \text { crore planned in five years, it will have } 5,000 \\
\text { beds in three-four phases, besides a medical college that } \\
\text { will admit } 200 \text { students from poor families, nursing and } \\
\text { paramedical institutions }\end{array}$ & 600 crore & 5000 \\
\hline
\end{tabular}

Table 2: Tertiary- level health diseases considered for the study of respondents.

1 General seasonal Infection 4 Stone cases, renal cases 7 Heart stent implant

$\begin{array}{llllll}2 & \text { Spinal cord operation } & 5 & \text { joint replacement } & 8 & \text { Lungs disorders } \\ 3 & \text { Heart by-pass surgery } & 6 & \text { Intestine problem } & & \end{array}$

Table 3: Inputs and outputs to calculate efficiency.

\begin{tabular}{ll} 
Inputs & Type \\
\hline No. of beds. & Numbers \\
Doctors & Numbers \\
Nurses & Numbers \\
Specialized equipment & Numbers \\
OPD hours per week & Hours \\
Laboratory hours per week & Hours \\
Paramedical staff & Numbers \\
Administrative staff & Numbers \\
Outputs & Type \\
Outpatient visits & Cases treated \\
Inpatients & Cases treated \\
laboratory cases & Cases treated \\
Maternal and child healthcare & Cases treated
\end{tabular}

Table 4: Effeciency analysis.

\begin{tabular}{ll}
\hline $\begin{array}{l}\text { Hospitals (Small Size) } \\
(\mathrm{n}=16)\end{array}$ & Efficiency \\
Mean & \\
Std. Dev. & 0.8 \\
Hospitals (Medium & 0.15 \\
Size) ( $\mathrm{n}=16)$ & \\
Mean & 0.75 \\
Std. Dev. & 0.16 \\
Hospitals (Large Size) \\
(n=16) \\
Mean \\
Std. Dev.
\end{tabular}


Table 5: Patient satisfaction analysis.

\begin{tabular}{ll}
\hline & Patient \\
Small Size Hospitals & Satisfaction \\
$(\mathrm{n}=16)$ & \\
Mean & 0.93 \\
Std. Dev. & 0.05 \\
Medium Size & \\
Hospitals $(\mathrm{n}=16)$ & \\
Mean & 0.88 \\
Std. Dev. & 0.07 \\
Large Size & $\cdot$ \\
Hospitals $(\mathrm{n}=16)$ & \\
Mean & 0.85 \\
Std. Dev. & 0.07
\end{tabular}

Table 6: Coefficient equation of model 1.

\begin{tabular}{lccccc}
\hline \multirow{2}{*}{ Model } & \multicolumn{2}{c}{$\begin{array}{c}\text { Unstandardized } \\
\text { Coefficients }\end{array}$} & $\begin{array}{c}\text { Standardized } \\
\text { Coefficients }\end{array}$ & $\mathrm{t}$ & Sig. \\
\cline { 2 - 6 } & $\mathrm{B}$ & Std. Error & Beta & & \\
\hline (Constant) & 3.553 & .259 & & 13.737 & .000 \\
size & -.33 & .001 & -2.186 & -5.675 & .002 \\
doctors & .186 & .006 & 1.802 & 4.476 & .000 \\
Efficiency & 4.061 & 5.051 & .420 & -2.531 & .065
\end{tabular}

Table 7: Coefficients model 2.

\begin{tabular}{|c|c|c|c|c|c|}
\hline \multirow[t]{2}{*}{ Model } & \multicolumn{2}{|c|}{$\begin{array}{l}\text { Unstandardized } \\
\text { Coefficients }\end{array}$} & \multirow{2}{*}{$\begin{array}{c}\text { Standardized } \\
\text { Coefficients } \\
\text { Beta }\end{array}$} & \multirow[t]{2}{*}{$\mathbf{t}$} & \multirow[t]{2}{*}{ Sig. } \\
\hline & B & Std. Error & & & \\
\hline (Constant) & 3.481 & .288 & & 12.099 & .001 \\
\hline size & -.314 & .001 & -2.196 & -5.406 & .002 \\
\hline doctors & .030 & .008 & 2.089 & 3.710 & .044 \\
\hline Efficiency & .531 & 1.233 & -.486 & -2.499 & .237 \\
\hline $\begin{array}{l}\text { Interaction } \\
\text { term }\end{array}$ & -.068 & .456 & -.281 & -.776 & .002 \\
\hline
\end{tabular}

Table 8: Regression analyses of low and high efficient hospitals.

\begin{tabular}{|lccc|}
\hline $\begin{array}{l}\text { Low efficient } \\
\text { hospitals }\end{array}$ & $\begin{array}{c}\text { Parameter } \\
\text { Estimate }\end{array}$ & Standard Error & Significance \\
\hline Specialized doctors & 0.172 & 0.051 & 0.048 \\
Hospital efficiency & -0.019 & 0.028 & 0.958 \\
Hospital size & --.314 & 0.001 & 0.153 \\
High efficient & & & \\
hospitals & & & \\
Specialized doctors & 0.026 & 0.036 & 0.246 \\
Hospital efficiency & -0.068 & 0.049 & 0.525 \\
Hospital size & -0.299 & 0.001 & 0.03 \\
\hline
\end{tabular}

As the connection between effectiveness and specialist is characterized by two techniques customary methodology and TQM approach. As hospitals dependably work with various economies of scale relationship is established in term of hospital estimate relationship coefficients are analyzed and found that there was negative relationship be tweens two variable for small size hospital as contended by conventional methodology no huge for medium measured and huge positive for huge size medical hospitals. There is the contrast between the connection of huge size and small size hospitals it implies customary methodology is upheld for small size medical hospitals of value trade-off while extensive hospitals work with TQM approach (Tables 7 \& 8).
Curiously, large size hospitals are not executing just as small and medium-size medical hospitals regarding scale effectiveness. In this way, these medical hospitals don't work at an ideal scale estimate. As recommended, expansive size medical hospitals may frame smaller patient consideration units inside their association. Along these lines, extensive size hospitals not just dispense with the negative impact of their non-ideal scale measure, yet also, they shape explicit treatment units for patients.

\section{CONCLUSION}

As indicated by research outcomes and findings, small size hospitals are generally more efficient and have higher patient satisfaction as compared to other hospitals. Large size hospitals provide good caliber of care than their small and medium-size partners. But still patients are more satisfied with small size hospitals might be reason is more expectation of patients from large size hospitals than from small size hospitals where patients have less expectation. Small size hospitals are more efficient and patients are more satisfied in this as already discussed might be both hospitals have different mission and vision. Presently medical hospital administration has a decision they can decide to overlook efficiencies also and simply focus on accomplishing highest caliber of care. Now an ideal arrangement may be "ideal and optimal care which could be accomplished by considering a "balance" between efficiency and quality.

This clarifies why numerous medical hospitals, particularly those in the corporate division, have started to work like a service industry. The medical hospital industry has started to utilize EHR experts and the board graduates. Outsider payers also have perceived that patient satisfaction is a significant instrument for the accomplishment of their association and are routinely checking patient satisfaction levels among their clients. In many hospitals rewards are connected to persistent assessment of their primary care physician's close to home communication with them. These players have perceived that higher patient satisfaction prompts benefits for the healthcare business in various manners, which have been bolstered by various investigations and present efficiency. Slack value will provide proper value in inputs need to be achieve target value.

Administration must plan policy to increase health coverage and network to all. Present research indicates that smaller hospitals have a higher level of efficiency than larger and medium-size hospitals, smaller size hospitals average efficiency is .80. The average efficiency of medium size hospitals is .75 and the large hospital is .73. As per our outcomes, small size medical hospitals are generally more efficient and have higher patient satisfaction as compared with other hospitals. It means Government must make a policy to implement small scale hospitals and cover more area to cover rural area. This will be accomplished through a staged presentation of medical coverage scheme(s) that will be done by promotion and appropriate arranging of healthcare assets. Government must create prepaid and pooled healthcare financing to lessen overdependence on out-of-pocket spending. The presentation of such prepayment systems will no doubt diminish the financial boundaries to access to medicinal services, and henceforth, add to improving the productivity of hospital. This study was the first to check the level and determinants of hospital framework productivity in Punjab dependent on quantitative and subjective research. This study also recommends that huge healthcare enhancements could be made without extra spending and that a portion of the variables that could help efficiency gains incorporate on the strength of the population. Huge population still can be served with existing infrastructure if hospitals will use operational analytics. 
Shortage of assets for healthcare is a well-recognized issue. The public segment of healthcare in India is lacking money related assets and lack of health professionals at all levels. In this circumstance, the effective usage of existing assets is essential for reinforcing the healthcare conveyance in the nation. The evaluation of the effectiveness of healthcare offices can help managers in guaranteeing the ideal usage of accessible assets. Data envelopment investigation has developed as a successful and well-known technique for assessing the efficiency of basic units in various areas of healthcare division. There have been various study's on evaluating the efficiency of medical hospitals and general medicinal services framework by utilizing DEA in various settings. Operational efficiency is the capacity to provide cost-effective and quality output from organization to the clients while maintaining the profit high. On account of medicinal services, this means hospitals and medical foundations having the option to give the best healthcare administrations to their patients while upgrading their operational expenses.

\section{LIMITATION OF STUDY}

As present research indicates that smaller hospitals have a higher level of efficiency than larger and medium-size hospitals, smaller size hospitals average efficiency is .80 . The average efficiency of medium size hospitals is .75 and the large hospital is .7. But each hospitals has different specialty and services which could be considered in future studies to benchmark input/output mix of hospitals for optimal working. But still data envelopment analysis based performance evaluation can be considered as useful tool by administration to check internal status of working of hospitals and apply performance indicators.

\section{REFERENCES}

1. Bowlin WF. Measuring performance: An introduction to data envelopment analysis (DEA). J Cost Anal. 1998;7:3-27.

2. Bhat $R$, Verma BB, Reuben E. Hospital efficiency and data envelopment analysis (DEA). An empirical analysis of district hospitals and grantin-aid hospitals in Gujarat state of India. Health Policy Development Network (HELPONET), India [IIM Ahmadabad] 2001:1-40.
3. Hassan M, Tuckman HP, Patrick RH, Kountz DS, Kohn JL. Hospital length of stay and probability of acquiring infection. Int J Pharm Health Mark. 2010;4:324-38.

4. Ghosh B, Bhadia U. A study on the inpatient system in a state hospital of Calcutta. Indian J Community Med. 1990;15:135-9.

5. Mogha SK, Yadav SP, Singh SP. Performance evaluation of Indian private hospitals using DEA approach with sensitivity analysis. Int J Adv Manage Econ. 2017;11:211-2.

6. Statistical abstract of Punjab, Available from https://punjab.gov.in/ [Last accessed on 18/7/2019].

7. Boussofiane A, Dyson RG, Thanassoulis E. Applied data envelopment analysis. Eur J Oper Res. 1991;52:1-15

8. Jat TR, Sebastian MS. Technical efficiency of public district hospitals in Madhya Pradesh, India: A data envelopment analysis. Glob Health Action. 2013;6:21742.

9. Kirigia JM, Emrouznejad A, Sambo LG, Munguti N, Liambila W. Using data envelopment analysis to measure the technical efficiency of public health centers in Kenya. J Med Syst. 2004;28:155-66.

10. Sheikhzadehl Y, Roudsari AV, Vahidi RG, Emrouznejad A, Dastgiri S. Public and private hospital services reform using data envelopment analysis to measure technical, scale, allocative, and cost efficiencies. Health Promot Perspect. 2012; 2:28-41.

11. Singh Z. Aging: The triumph of humanity-are we prepared to face the challenge? Indian J Public Health. 2012;56:189-95.

12. Singh $P$, Farhan $M$, Asif $M$. An empirical study on association of operational efficiency and customer satisfaction in tertiary hospitals in Punjab, Indian Journal of Public Health Research \& Development, 2019, Vol. 10 Issue 9, p295-301. 7p

13. Davey S, Raghav SK, Muzammil K, Singh JV, Davey A, Singh SK, et al. Study on role of rural health training centre (RHTC) as a supporting component to a primary health care system for NRHM programme in district Muzaffarnagar (UP). Int J Res Med Sci. 2014;2:653-61.

Cite this article: Akula SC, Singh P. Modeling relation between hospital efficiency and customer satisfaction of tertiary hospitals: A case of data envelopment analysis. Pharmacogn J. 2021;13(6): 1527-1532. 